\title{
Epidemiological analysis of carbapenem-sensitive and -resistant Pseudomonas aeruginosa
}

\author{
F. Walsh ${ }^{a, *}$, S. Bracher ${ }^{\text {b }}$, P. Turner ${ }^{\text {b }}$, S.G.B. Amyes ${ }^{a}$ \\ a Medical Microbiology, University of Edinburgh, Teviot Place, Edinburgh EH8 9AG, UK \\ ${ }^{\mathrm{b}}$ AstraZeneca plc, Alderley Park, Cheshire, UK
}

Received 27 July 2004; accepted 17 December 2004

Available online 22 March 2005

\section{KEYWORDS \\ Pulsed-field gel \\ electrophoresis; \\ Carbapenem; \\ Genotype; \\ Pseudomonas \\ aeruginosa; \\ Epidemiology}

\begin{abstract}
Summary Pseudomonas aeruginosa with decreased levels of meropenem susceptibility were identified in the Royal Infirmary Edinburgh in 2002. Within the affected group of patients, none had meropenem-resistant $P$. aeruginosa when they arrived in the intensive care unit (ICU). Seven isolates from the ICU were collected five months after the decreased susceptibility to meropenem was identified. In order to investigate if resistance was a problem in $P$. aeruginosa throughout Edinburgh, both in hospital- and community-acquired isolates, a prospective study was performed. The susceptibilities of $104 P$. aeruginosa to imipenem, meropenem, ceftazidime, piperacillin/tazobactam and ciprofloxacin were investigated. Meropenem had the highest activity against these isolates and the lowest $\mathrm{MIC}_{90}(2 \mathrm{mg} / \mathrm{L})$, followed by imipenem $(4 \mathrm{mg} / \mathrm{L})$, ciprofloxacin $(8 \mathrm{mg} / \mathrm{L})$, piperacillin/tazobactam $(16 \mathrm{mg} / \mathrm{L})$ and ceftazidime $(32 \mathrm{mg} / \mathrm{L})$. These isolates were also analysed genotypically by pulsed-field gel electrophoresis. Five of the seven ICU isolates were identified, one isolate was $98 \%$ similar and the other was $85 \%$ similar to the ICU isolates. One isolate from the prospective study had approximately $90 \%$ genotype similarity to the six ICU isolates with $\geq 98 \%$ similarity. There was no clonality within the strains from the prospective study and clusters with $>90 \%$ similarity comprised at five or less isolates. Isolates with the same resistance patterns did not necessarily have the same genotypic profile. Strains isolated from different patients on the same day were also not necessarily related. The conclusions of this study were that while the seven ICU isolates were clonal or highly related, they were not widespread throughout Edinburgh and the $P$. aeruginosa within Edinburgh were highly varied.

(c) 2005 The Hospital Infection Society. Published by Elsevier Ltd. All rights reserved.
\end{abstract}

\footnotetext{
* Corresponding author. Tel.: +44 131 6511533; fax: +44 1316511385.

E-mail address: fwalsh@staffmail.ed.ac.uk
} 
Table I Susceptibility profiles of the outbreak isolates

\begin{tabular}{lccccc}
\hline Strain ID & $\begin{array}{c}\text { Imipenem MIC } \\
(\mathrm{mg} / \mathrm{L})\end{array}$ & $\begin{array}{c}\text { Meropenem MIC } \\
(\mathrm{mg} / \mathrm{L})\end{array}$ & $\begin{array}{c}\text { Ceftazidime MIC } \\
(\mathrm{mg} / \mathrm{L})\end{array}$ & $\begin{array}{c}\text { Piperacillin/ } \\
\text { tazobactam } M I C \\
(\mathrm{mg} / \mathrm{L})\end{array}$ & $\begin{array}{c}\text { Ciprofloxacin } M I C \\
(\mathrm{mg} / \mathrm{L})\end{array}$ \\
\hline 01 & $16 \mathrm{R}$ & $16 \mathrm{R}$ & 4 & $32 \mathrm{R}$ & $16 \mathrm{R}$ \\
02 & $8 \mathrm{R}$ & 4 & $32 \mathrm{R}$ & 8 & $8 \mathrm{R}$ \\
03 & 4 & 4 & 2 & 4 & $8 \mathrm{R}$ \\
04 & 2 & 0.5 & 4 & 4 & 0.12 \\
05 & 4 & $8 \mathrm{R}$ & 2 & 8 & $16 \mathrm{R}$ \\
06 & 0.5 & 0.25 & 2 & 4 & $8 \mathrm{R}$ \\
07 & 4 & $8 \mathrm{R}$ & 2 & 8 & $16 \mathrm{R}$ \\
\hline
\end{tabular}

$\mathrm{R}$, resistant; MIC, minimum inhibitory concentration.

\section{Introduction}

Pseudomonas aeruginosa is the second most frequently reported pathogen overall in intensivecare-unit (ICU)-acquired infections in Europe. ${ }^{1}$ It is of particular concern for intubated and/or immunocompromised patients. The antimicrobial agents most commonly used to treat $P$. aeruginosa infections are meropenem, imipenem, ceftazadime, piperacillin/tazobactam and ciprofloxacin. However, resistance to imipenem is increasing; in recent years, it has increased to between $12 \%$ and $18 \% .{ }^{1}$ Resistance to other therapeutic agents varied from $9.8 \%$ for meropenem to $25 \%$ for ciprofloxacin.

There is an awareness of the ever-decreasing number of available therapeutic options. Therefore, it is important to understand the origins of resistance in order to minimize its transmission and spread. When an outbreak of resistant isolates occurs within a hospital, it is important to understand whether the outbreak is caused by a single clone or multiple isolates, and whether they have resistance to all available antimicrobial agents or specifically to one antimicrobial agent. There are various techniques available to analyse similarity or diversity of bacterial isolates. Pulsed-field gel electrophoresis (PFGE) is one such method, which is preferred to other typing methods by many laboratories for the epidemiological study of bacteria, such as $P$. aeruginosa. ${ }^{2}$

The aims of this study were firstly to identify whether resistant $P$. aeruginosa were widespread in hospitals and the community in Edinburgh. Secondly, as resistance in the ICU appeared within days, we decided to analyse the Edinburgh cohort genotypically to investigate whether there was a clonal relationship between $P$. aeruginosa with the same and different resistance patterns, i.e. to elucidate whether sensitive isolates were of the same genotype as resistant isolates, and to investigate whether there was a genotypic link between hospital- and community-acquired $P$. aeruginosa.

\section{Materials and methods}

\section{Bacterial strains and susceptibility testing}

Seven resistant $P$. aeruginosa isolates from the ICU with the initial meropenem resistance problem were collected in December and early January of 2002 and 2003, respectively. These isolates were identified as meropenem resistant by the Royal Infirmary Edinburgh. One hundred and four $P$. aeruginosa strains, 23 from community-acquired infections and 81 from hospital-acquired infections, identified by the diagnostic laboratories at the Royal Infirmary Edinburgh were collected between January and May 2003. The antimicrobial agents were obtained from their respective manufacturers and were stored and prepared according to the manufacturers' guidelines. The susceptibilities of the $P$. aeruginosa to imipenem, meropenem, ceftazidime, piperacillin/tazobactam and ciprofloxacin were determined by agar dilution in vitro, according to the British Society for Antimicrobial Chemotherapy (BSAC) guidelines. ${ }^{3}$ The antimicrobial breakpoints were assigned at the following minimum inhibitory concentration (MIC) values according to the BSAC guidelines: imipenem $\geq 8 \mathrm{mg} / \mathrm{L}$; meropenem $\geq 8 \mathrm{mg} / \mathrm{L}$; ceftazidime $\geq 16 \mathrm{mg} / \mathrm{L}$; piperacillin/tazobactam $\geq 32 \mathrm{mg} / \mathrm{L}$; and ciprofloxacin $\geq 2 \mathrm{mg} / \mathrm{L}$. ${ }^{4}$

\section{PFGE analysis}

All isolates were genotyped by PFGE (CHEF DR II system, BioRad, Hemel Hempstead, Hertfordshire, UK) following total bacterial DNA digestion with the 
Table II Susceptibility profiles of the 104 prospective study isolates

\begin{tabular}{lllc}
\hline $\begin{array}{l}\text { Antimicrobial } \\
\text { agents }\end{array}$ & $\begin{array}{c}\text { Range } \\
(\mathrm{mg} / \mathrm{L})\end{array}$ & $\begin{array}{c}\mathrm{MIC}_{50} \\
(\mathrm{mg} / \mathrm{L})\end{array}$ & $\begin{array}{c}\mathrm{MIC}_{90} \\
(\mathrm{mg} / \mathrm{L})\end{array}$ \\
\hline Imipenem & $0.5-32$ & 2 & 4 \\
Meropenem & $0.032-16$ & 0.25 & 2 \\
Ceftazidime & $0.5-32$ & 2 & 32 \\
Piperacillin/ & $0.5-128$ & 4 & 16 \\
tazobactam & & & \\
Ciprofloxacin & $0.016-32$ & 0.25 & 8 \\
\hline
\end{tabular}

MIC, minimum inhibitory concentration.

endonuclease Xba I. The method of Cheng et al. was used with the following alteration: a suspension of a single colony of each isolate was made in buffer (4.38\% $\mathrm{NaCl}, 9.3 \% \mathrm{EDTANa}_{2}, 86.32 \%$ distilled water) and mixed with molten $1 \%$ low-melting-point preparative-grade agarose instead of overnight broth culture. ${ }^{5}$ The macrorestriction patterns were compared by Bionumerics ${ }^{\circledR}$ software (Applied Maths, Sint-Martens-Latem, Belgium). The percent relatedness was calculated using the Dice coefficient, and the unweighted pair group method with arithmetic averages was used for cluster analysis to produce a dendogram with band optimization settings of $1.00 \%$ and a band tolerance position of $1.0-2.0 \%$.

\section{Results}

\section{Phenotypic characteristics}

The susceptibility profiles of the seven outbreak isolates are shown in Table I.

The prospective study had the following rates of

Table III Clustered susceptibility profiles of the 104 prospective study isolates

\begin{tabular}{|c|c|c|c|c|c|}
\hline Isolate & $\begin{array}{l}\text { Imipenem MIC } \\
(\mathrm{mg} / \mathrm{L})\end{array}$ & $\begin{array}{c}\text { Meropenem MIC } \\
(\mathrm{mg} / \mathrm{L})\end{array}$ & $\begin{array}{c}\text { Ceftazidime MIC } \\
(\mathrm{mg} / \mathrm{L})\end{array}$ & $\begin{array}{c}\text { Piperacillin/ } \\
\text { tazobactam MIC } \\
(\mathrm{mg} / \mathrm{L})\end{array}$ & $\begin{array}{c}\text { Ciprofloxacin MIC } \\
(\mathrm{mg} / \mathrm{L})\end{array}$ \\
\hline PaFW 46 & $32 \mathrm{R}$ & 4 & $32 \mathrm{R}$ & $32 \mathrm{R}$ & $2 R$ \\
\hline PaFW 10 & 2 & 0.25 & $32 \mathrm{R}$ & $64 \mathrm{R}$ & $8 \mathrm{R}$ \\
\hline PaFW 14 & $16 \mathrm{R}$ & $16 \mathrm{R}$ & 8 & 16 & $8 \mathrm{R}$ \\
\hline PaFW 50 & 4 & 0.5 & $32 \mathrm{R}$ & $32 \mathrm{R}$ & $4 \mathrm{R}$ \\
\hline PaFW 110 & $16 \mathrm{R}$ & $16 \mathrm{R}$ & 2 & 4 & $8 \mathrm{R}$ \\
\hline PaFW 3 & 2 & 1 & $32 \mathrm{R}$ & 4 & $32 \mathrm{R}$ \\
\hline PaFW 19 & 1 & 2 & $32 \mathrm{R}$ & 4 & $32 \mathrm{R}$ \\
\hline PaFW 21 & 2 & 0.5 & $32 \mathrm{R}$ & $32 \mathrm{R}$ & 0.12 \\
\hline PaFW 29 & $16 \mathrm{R}$ & 4 & $32 \mathrm{R}$ & 4 & 0.12 \\
\hline PaFW 65 & 1 & 0.12 & $32 \mathrm{R}$ & $128 \mathrm{R}$ & 1 \\
\hline PaFW 95 & $8 \mathrm{R}$ & 4 & 8 & 16 & $2 \mathrm{R}$ \\
\hline PaFW 7 & 1 & 2 & $32 \mathrm{R}$ & 8 & 1 \\
\hline PaFW 16 & 1 & 0.5 & 4 & 16 & $32 \mathrm{R}$ \\
\hline PaFW 23 & 0.5 & 0.25 & 2 & 4 & $8 \mathrm{R}$ \\
\hline PaFW 24 & 2 & 1 & $32 \mathrm{R}$ & 4 & 0.12 \\
\hline PaFW 25 & 2 & 2 & $32 \mathrm{R}$ & 16 & 0.5 \\
\hline PaFW 26 & 1 & 0.25 & 8 & 16 & $4 \mathrm{R}$ \\
\hline PaFW 34 & 1 & 0.5 & $32 \mathrm{R}$ & 8 & 0.25 \\
\hline PaFW 37 & 4 & 2 & 2 & 4 & $8 \mathrm{R}$ \\
\hline PaFW 59 & 0.5 & 0.032 & 1 & 0.5 & $2 \mathrm{R}$ \\
\hline PaFW 60 & 4 & 0.25 & 2 & 0.5 & $2 \mathrm{R}$ \\
\hline PaFW 61 & 2 & 0.5 & 8 & 4 & $2 \mathrm{R}$ \\
\hline PaFW 62 & 2 & 1 & $16 \mathrm{R}$ & 4 & 1 \\
\hline PaFW 63 & 2 & 0.25 & 4 & 8 & $8 \mathrm{R}$ \\
\hline PaFW 71 & 2 & 0.25 & 2 & 4 & $4 \mathrm{R}$ \\
\hline PaFW 80 & 4 & 0.12 & 4 & 8 & $8 R$ \\
\hline PaFW 85 & 2 & 0.12 & 2 & 4 & $4 \mathrm{R}$ \\
\hline PaFW 93 & $32 \mathrm{R}$ & 4 & 1 & 2 & 0.12 \\
\hline PaFW 102 & 2 & 0.5 & 8 & 8 & $16 \mathrm{R}$ \\
\hline PaFW 108 & 4 & 0.25 & $16 \mathrm{R}$ & 16 & 0.25 \\
\hline PaFW 111 & 2 & 0.25 & 2 & 4 & $4 \mathrm{R}$ \\
\hline
\end{tabular}

$\mathrm{R}$, resistant; MIC, minimum inhibitory concentration. 

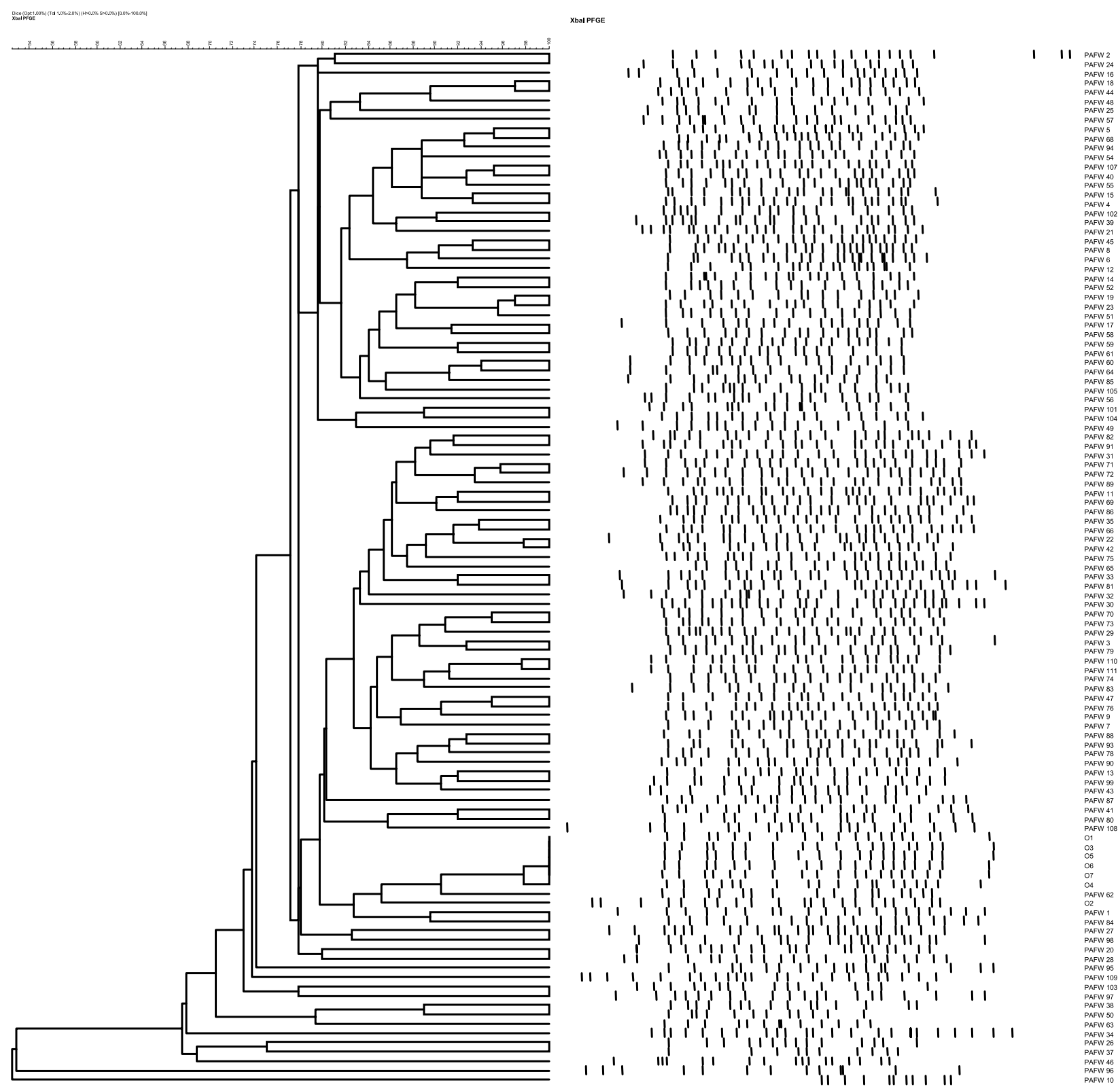

Figure 1 Cluster analysis dendogram of Pseudomonas aeruginosa isolates showing the percent similarities and resistance profiles of the isolates.

resistance: ciprofloxacin 20\%; ceftazidime $13.5 \%$; imipenem 5.8\%; piperacillin/tazobactam $4.8 \%$; and meropenem $1.9 \%$. The $\mathrm{MIC}$ range, $\mathrm{MIC}_{50}$ and $\mathrm{MIC}_{90}$ of meropenem was the lowest of the five antimicrobial agents against the 104 isolates as indicated in Table II. The isolates were numbered in the order in which they were collected, i.e. PaFW 1 was the isolate collected first. The MICs for each cluster of isolates against the five antimicrobial agents are described in Table III.

\section{PFGE analysis}

PFGE analysis of all of the isolates showed rates of similarity from $52 \%$ to $100 \%$ on the dendogram using the BioNumerics software analysis (Figure 1). Most of the isolates had $>75 \%$ similarity. Five of the seven initial isolates had $100 \%$ similarity, one isolate was $98 \%$ similar and the other was $85 \%$ similar to the other outbreak isolates. Isolate PaFW 62 had approximately $90 \%$ genotype similarity to the six outbreak isolates with similarities of $\geq 98 \%$. These seven isolates formed the only major cluster of the isolates genotyped. No other cluster had comparable percent similarities. While most of the isolates had $>75 \%$ similarity, clusters with $>90 \%$ similarity contained at five or less isolates. Within 
these small groups, the isolates were not necessarily isolated at the same time; PaFW 9, PaFW 47 and PaFW 76 had $90 \%$ similarity. Isolates with the same patterns of resistance were also not clustered together. There was no genotypic similarity pattern to suggest that resistant or susceptible isolates have spread from the community to the hospital or vice versa. There was also little similarity to the outbreak isolates; the sequence similarity of the 104 prospective study isolates was $<82 \%$ similar to the outbreak isolates.

\section{Discussion}

This study provides the first published data on the genetic relatedness of hospital isolates of $P$. aeruginosa resistant to antibacterial agents and susceptible $P$. aeruginosa from different and the same sites of isolation in the UK. PFGE has been shown to be an excellent epidemiological tool for the discrimination of related and unrelated isolates of $P$. aeruginosa. ${ }^{6,7}$ Tenover et al. defined categories of genetic and epidemiological relatedness of isolates using PFGE. ${ }^{8}$ However, they suggested that these guidelines should be used to examine relatively small sets of isolates (typically $\leq 30$ ) related to putative outbreaks of disease. Therefore, these guidelines were not used to analyse the 111 isolates of this study.

The results of this study have shown that only seven of the isolates were closely related, six of which were associated with the outbreak and one was a non-outbreak isolate. One of the outbreak isolates was genetically distinct from the others. This indicates that while the outbreak was most probably caused by one clone, at least one other type of strain/clone was also involved. These isolates also had varying resistance profiles. The reasons for this could be that either the resistance associated with the original clone was modified as the selective pressure of the antimicrobial agent was removed, or isolates with the same genetics had different resistance mechanisms. All the isolates had a level of relatedness associated as being part of the same species, but were not related to such an extent that they were clonal. Therefore, the outbreak did not persist and normal infection control measures have eradicated the problem.
No clonality existed within either the resistant or sensitive $P$. aeruginosa isolated. This study suggests that none of the genotypes present were predisposed to the acquisition of resistance genes, nor did one type persist more than the others. Thus, there has not been a specific type or clone that has established itself within Edinburgh. The conclusions of this study were that while the outbreak isolates were clonal or highly related, they did not persist or spread to other areas within Edinburgh, as indicated by the prospective study. The prospective study isolates were very heterogeneous and resistant clones were not selected from the strains within this environment.

\section{Acknowledgements}

This project was funded by AstraZeneca plc. We would like to thank $\operatorname{Dr} C$. Doherty for her help with the PFGE.

\section{References}

1. Kirby JT, Mutnick AH, Jones RN, et al. Geographic variations in activity of broad-spectrum $\beta$-lactams against Pseudomonas aeruginosa: summary of the worldwide SENTRY antimicrobial surveillance program (1997-2000). Diagn Microbiol Infect Dis 2002;43:239-243.

2. Jones AM, Govan JRW, Doherty CJ, et al. Identification of airborne dissemination of epidemic multiresistant strains of Pseudomonas aeruginosa at a CF centre during a cross infection outbreak. Thorax 2003;58:525-527.

3. Andrews JM. Determination of minimum inhibitory concentrations. J Antimicrob Chemother 2001;48(Suppl. 1):5-16.

4. MacGowan AP, Wise R. Establishing MIC breakpoints and the interpretation of in vitro susceptibility tests. J Antimicrob Chemother 2001;48(Suppl. 1):17-28.

5. Cheng K, Smyth RL, Govan JRW, et al. Spread of $\beta$-lactamresistant Pseudomonas aeruginosa in a cystic fibrosis clinic. Lancet 1996;348:639-642.

6. Grundmann H, Schneider C, Hartung D, et al. Discriminatory power of three DNA-based typing techniques for Pseudomonas aeruginosa. J Clin Microbiol 1995;33:528-534.

7. Thuong M, Arvaniti K, Ruimy R, et al. Epidemiology of Pseudomonas aeruginosa and risk factors for carriage acquisition in an intensive care unit. J Hosp Infect 2003;53: 274-282.

8. Tenover FC, Arbeit RD, Goering RV, et al. Interpreting chromosomal DNA restriction patterns produced by pulsedfield gel electrophoresis: criteria for bacterial strain typing. J Clin Microbiol 1995;33:2233-2239. 